\title{
Simulation and bench studies of the constructively and technologically modernized high performance piston aircraft engine. Stage I
}

\author{
W. OSTAPSKI ${ }^{1 *}$, T. WIERZCHON' ${ }^{2}$, J. RUDNICKI $^{2}$, and S. DOWKONTT ${ }^{1}$ \\ ${ }^{1}$ Institute of Machine Design Fundamentals, Warsaw University of Technology, 84 Narbutta St., 02-524 Warsaw, Poland \\ ${ }^{2}$ Faculty of Materials Science and Engineering, Warsaw University of Technology, 141 Wołoska St., 02-507 Warsaw, Poland
}

\begin{abstract}
The paper presents an analysis of tribological wear of an assembly composed of cylinder liner and piston rings in a piston aircraft engine. In place of the previously used technology of gas nitriding of the cylinder liner (made out of 38CrAlMo6-10 steel), formation of multi-component or composite layers by nitriding in plasma discharge environment was proposed. Also, a modification of the previously used chromium coating of the piston rings by plasma nitriding was proposed. A study on the structure and properties of surface layer diffusion manufactured by utilizing the phenomenon of cathode sputtering was carried out. Wear resistance tests were performed on a specially designed bench, with the use of isotope markers. Verification of each of the friction couples was based on using the wear of the ring as a function of the distance trip, and the roughness of the cylinder liner and ring.
\end{abstract}

Key words: aircraft, piston, engine, plasma, nitriding.

\section{Introduction}

Operational problems of ASz62-IR engines and the loss of competitiveness on the aerial engine market have led to a significant modernization. This mainly applies to an increase in the service interval, increase in power, and a reduction of fuel and oil consumption and vibration levels, while maintaining the current size and weight of the engine. This involves major design changes and technological developments to the engine. Increasing the service interval requires an increase in the sustainability of the elements and components in general, specifically of the components responsible for engine safety. During a periodic inspection, cases of fatigue damage of such elements and components, due to the high load, were found. The planned increase of the mentioned parameters by $20 \%$ has increased the likelihood of damages. The planned power increase, while improving service intervals, excessively increased the load on the existing crank-piston system. It was necessary to redesign the main, and optional to redesign the secondary connecting rod assembly.

For the increased mechanical load (air pressure) in the cylinder unit, additional thermal loads were added. Stainless steel cylinder liners were connected with aluminum alloy heads using a threaded coupling and a friction fit (shrink connection). Assurance that the connection will be maintained was reached by not exceeding the critical temperature of the air-cooled cylinder head. The increased mechanical and thermal loads affect the valve set, particularly the exhaust valves. An important problem to solve was the uneven wear of tribological couplings in cyl-

*e-mail: wos@simr.pw.edu.pl inder liners and piston rings. It derives from the principle of the crankshaft operation (lateral forces on the piston in a plane normal to the piston pin), and non-uniform thermal deformation, particularly in the region of the external piston turning point. In the context of increased operational period and engine power, there was a need to significantly modify the existing manufacturing technology of cylinder liners, rings, and cooling system.

The research was multi-threaded and was focused on creating an improved version of the high-performance piston aircraft engine.

Because of the volume of material obtained due to the longterm cooperation with the industry, the authors find it best to present the work in stages.

The authors establish the first stage of this work in relation to prolonging the life of the cylinder assembly of the high-performance piston aircraft engine using surface engineering technology.

\section{Analysis of wear and tear of cylinder assembly}

The measurements of profiles of piston rings and deviations from the circularity of the cylinder liners in subsequent cross-sections (normal to the axis) and sections forming the cylinder, carried out during the inspections of disassembled engines, conducted during periodic reviews (after 1200 hours of operation), showed a significant variation of the deviations from the nominal diameter and the position of the extremes of deviation from the plane of action of the reaction time [1].

Most of the values obtained during the measurements had their maximum resolution of wear in the zones of turning positions of the piston. However, around $30 \%$ of the cylinders have 
the maximum wear (in cross-sections normal to the cylinder axis) shifted by approximately $45^{\circ}$ relative to the parting plane of the body. The body of the ASz-62IR engine is divided. The plane of action of the reaction torque coincides with the parting plane of the body. At that plane, it was possible to rotate the piston relative to the pin, and here we would expect increased consumption that takes away the cylinder liner. However, if you take into account the differentiated thermal deformation caused by the airflow around the cylinder liner, such a shift in maximum wear is justified. This is mainly dependent on the application and the correct settings of deflectors. The analysis of the influence of mechanical stresses and irregular thermal loads on the state of stress and strain in the cylinder liner of the ASz-62IR engine is shown in [1].

Additional causes of such character of distribution may be:

- Excessive tolerances in the elements of the cylinder liner and its socket in the engine housing.

- Misalignment of the cylinder liner relative to the socket in the engine housing, uncompensated by permitted axial and radial displacement of the connecting rods.

- Excessive dynamic lateral forces causing the piston to swing.

- Large clearances between the piston and cylinder wall in the cold engine.

The worst case of the eccentric mounting occurs when the maximum lies in a plane rotated by $45^{\circ}$ relative to the plane of action of the reaction torque. In this case, there are larger lateral forces occurring than in the case where the deviation misalignment of the cylinder liner and the socket in the engine housing lies in the plane of the reaction torque of the engine. If the difference lies in the plane of the piston pin axis, the lateral force will be greater than it would be in the case where the deviation lies in the plane of torque. However, it will be less than it would be in the case when the position of the deviation in a plane was rotated by $45^{\circ}$ relative to the plane of action of the reaction torque. This happens due to the fact that the movement in the worst case will be more complex: rotation and travel along the pin will be present, causing strong spatial oscillations of the piston. The other two extreme cases of the position deviation were the rotation or sliding of the piston. In each of these cases, there is the pendulum movement of the piston, irrespective of the application of predetermined eccentricity of the location of the pin, relative to the plane of symmetry of the piston. The presence of significant lateral forces acting on the piston and pin, leading to spatial oscillations of the piston, leads to flanging of the piston rings and their function in extremely unfavorable conditions (increased pressure and working under boundary friction). In several cases, there was direct striking contact between the piston skirt and the cylinder wall, resulting in plasticity deformation.

Under these conditions, the friction couple - the piston ring and cylinder liner - in a reciprocating movement, with the increase of clearances, causes further increasing lateral dynamic forces [2]. Reduced engine life due to wear and corrosion is a consequence not only of the existing technology of surface treatment of the cylinder and rings, but also of errors made during the construction.

\section{Technology of manufacturing anti-wear diffusion layers in components of piston aircraft engine}

A preliminary analysis of the factory data in search of reasons for damage and reduced operating capacity of the ASz-62IR engine $[1,2]$ indicated a few sources of these problems [2].

One of the most important ones is the excessive wear and corrosion of the cylinder and piston rings unit. This paper presents the results of a research into the improvement of the tribological cylinder and piston rings unit. It proposed the formation of nitrided layers and composite in processes of nitriding, oxygen and carbonation nitriding in plasma discharge conditions in place of previously used gas nitriding of cylinder liner (made out of 38CrAlMo6-10 steel) [3,4]. There was also a proposed modification of the chromium coating formed on the piston rings by the plasma nitriding process $[5,6]$.

A study was conducted on the structure and properties of the produced surface layers (Figs. 1-6). Figs. 1 and 2 show the results of wear resistance of layers produced by "three

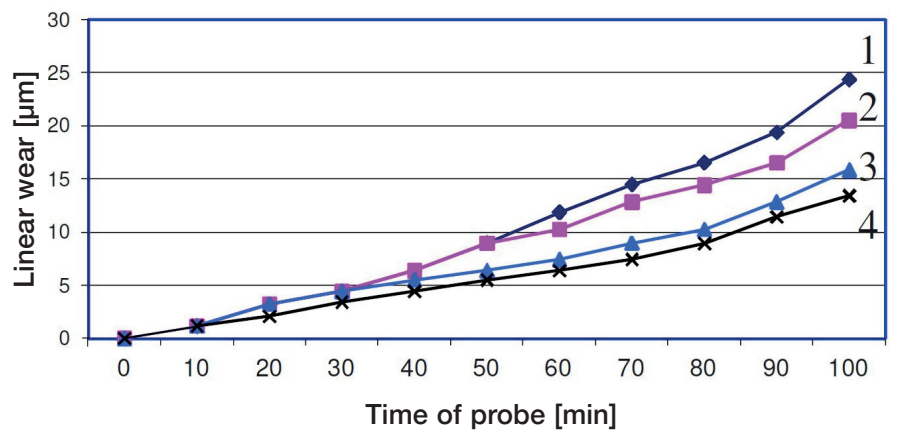

Fig. 1. Wear of the diffusion layers on the 38CrAlMo6-10 steel surface at a pressure of $400 \mathrm{MPa}$ in unconsolidated method of "three rollers + taper": 1 - nitrided layer of nitride zone $\mathrm{Fe}_{4} \mathrm{~N}+\mathrm{Fe}_{2-3} \mathrm{~N}$ with a thickness of $25 \mu \mathrm{m}, 2$ - nitrided layer without the transition zone nitrides iron, 3 - layer oxynitriding $-\mathrm{Fe}_{3} \mathrm{O}_{4}(2 \mu \mathrm{m})+\mathrm{Fe}_{4} \mathrm{~N}+10 \mu \mathrm{m}$ $\mathrm{Fe}_{2-3} \mathrm{~N}(10 \mu \mathrm{m})$, transition zone $(250 \mu \mathrm{m}), 4$ - oxygen and carbonation nitriding $\mathrm{Fe}_{3} \mathrm{O}_{4}+\left(\mathrm{Fe}_{2-3} \mathrm{~N}+\mathrm{Fe}_{4} \mathrm{~N}\right)+$ transition zone of precipitates of carbonation nitrides of iron into the iron nitride zone

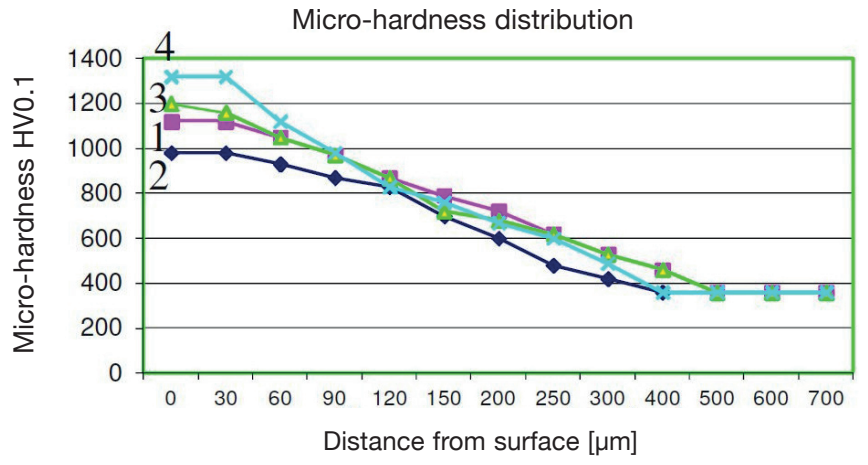

Fig. 2. Cumulative distributions of micro-hardness HV0.1: 1 - nitrided layer of nitride zone $\mathrm{Fe}_{4} \mathrm{~N}+\mathrm{Fe}_{2-3} \mathrm{~N}$ with a thickness of $25 \mu \mathrm{m}, 2-$ nitrided transition zone without the zone of iron nitrides, 3 - layer oxygen nitriding $-\mathrm{Fe}_{3} \mathrm{O}_{4}(2 \mu \mathrm{m})+\mathrm{Fe}_{4} \mathrm{~N}+\mathrm{Fe}_{2-3} \mathrm{~N}(10 \mu \mathrm{m})$ transition zone $(250 \mu \mathrm{m}), 4-$ oxygen and carbon nitriding $\mathrm{Fe}_{3} \mathrm{O}_{4}+\left(\mathrm{Fe}_{2-3} \mathrm{~N}+\mathrm{Fe}_{4} \mathrm{~N}\right)$ + transition zone of iron carbon nitrides under the iron nitride zone 
rolls + cone" [7]. Studies have shown that diffusion layers obtained on 38CrAlMo6-10 steel are characterized by high resistance to friction wear (Fig. 1), best in layers after the process of oxygen nitriding. It should be emphasized that an important role in the formation of the diffusion layers is played by the sputtering process during the heating of elements to the process temperature. This makes it possible for the layers created on parts with complex shapes to have uniform thickness. It has been shown that in process temperatures up to $560^{\circ} \mathrm{C}$, in the outer layer, an outer zone $\mathrm{Fe}_{4} \mathrm{~N}+\mathrm{Fe}_{2-3} \mathrm{~N}$, known as the transition zone, with a thickness of 250 microns is formed by iron nitride. It was found that increasing the temperature in the range $520-560^{\circ} \mathrm{C}$ increases the thickness of the area of nitrides in the nitrided layer by up to approximately $25 \mu \mathrm{m}$ for a temperature of $560^{\circ} \mathrm{C}$ in a $12 \mathrm{~h}$ process. Micro-hardness of the surface layer produced was in the range 980-1300 HV0.1 (Fig. 2).

The oxygen and carbon nitrided layer has the highest hardness of the surface layer (4). The nitrided layer of the nitride zone (1) and the oxygen nitrided layer (3) have a similar surface micro-hardness. The transition zone shows the lowest hardness. Microstructures of the layers created on 38CrAlMo6-10 steel in selected processes are shown in Figs. 3-6. In the created layers there are compressive stresses. Such distribution of stresses in the nitrided component is advantageous, because it allows for an increased fatigue strength of the processed parts [2].

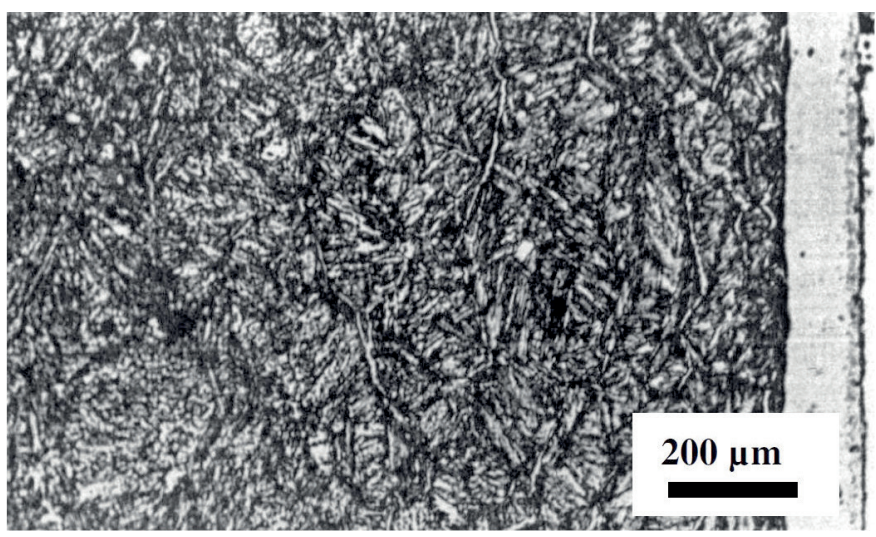

Fig. 3. The microstructure of nitrided layers of the nitride diffusion zone $\left(\mathrm{Fe}_{2-3} \mathrm{~N}+\mathrm{Fe}_{4} \mathrm{~N}\right)$

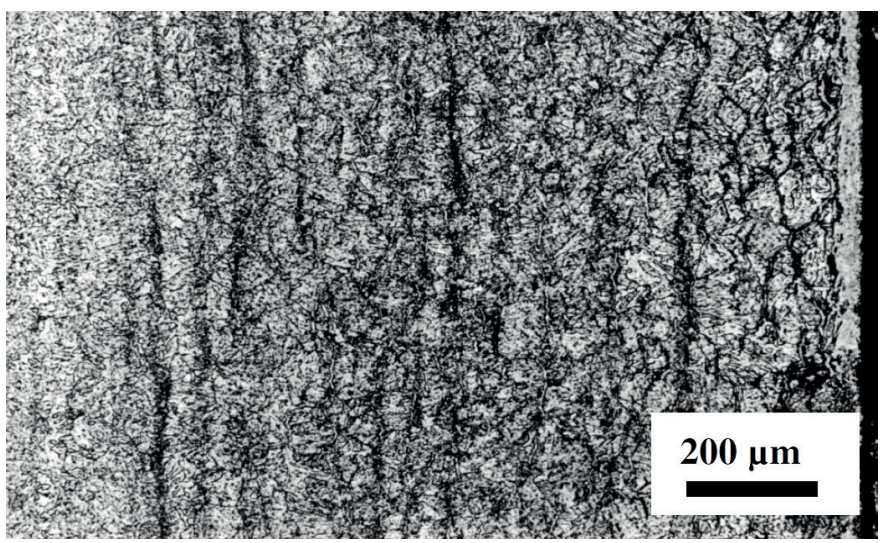

Fig. 5. The microstructure of nitrided layers of oxygen diffusion
The thickness of the zone of nitrides in the nitrided layer is small compared to the thickness of nitrided elements. For this reason, there is often too high of a tension gradient between the nitrided layer, particularly the outer zones of nitrides of iron, and the core. It may be a disadvantage, especially when the working component is subjected to dynamic loads or high surface pressure. In extreme cases, there may be flaking of nitrides in the area, and hence deterioration in the performance of the nitrided element. For these reasons, it is preferable that changes in stress from the surface nitrided component to its core are as gentle as possible. As is known, residual stresses in the nitrided layer depend mainly on the phase composition and the nitrogen content in the layer of the transition zone [8]. The nitriding process creates opportunities for the production of nitrided layers of a well-defined composition phase (Figs. 3-6).

The use of plasma discharge nitriding, as compared with the conventional method of gas nitriding treatment of aircraft engine components, allows for:

- energy efficiency of the process by reducing the nitriding time by about $30-40 \%$ and heating the work pieces only in low temperature plasma;

- ecological purity of the technological process by replacing ammonia with either a mixture of $\mathrm{H}_{2}+\mathrm{N}_{2}$ or $\mathrm{N}_{2}$-only nitriding process or $\mathrm{H}_{2}+\mathrm{NB}+\mathrm{CH}_{4}$ (up to $10 \%$ ) carbon

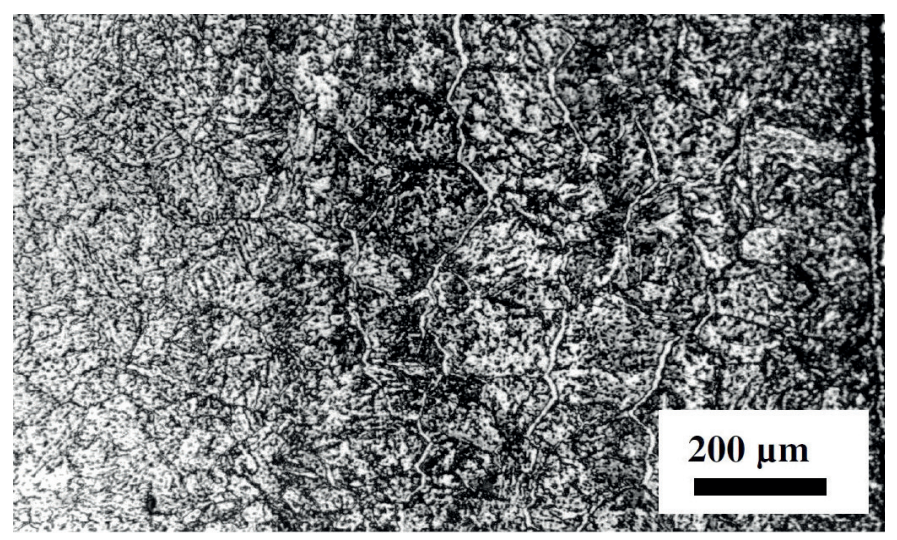

Fig. 4. The microstructure of nitrided layers of diffusion without the nitride diffusion zone

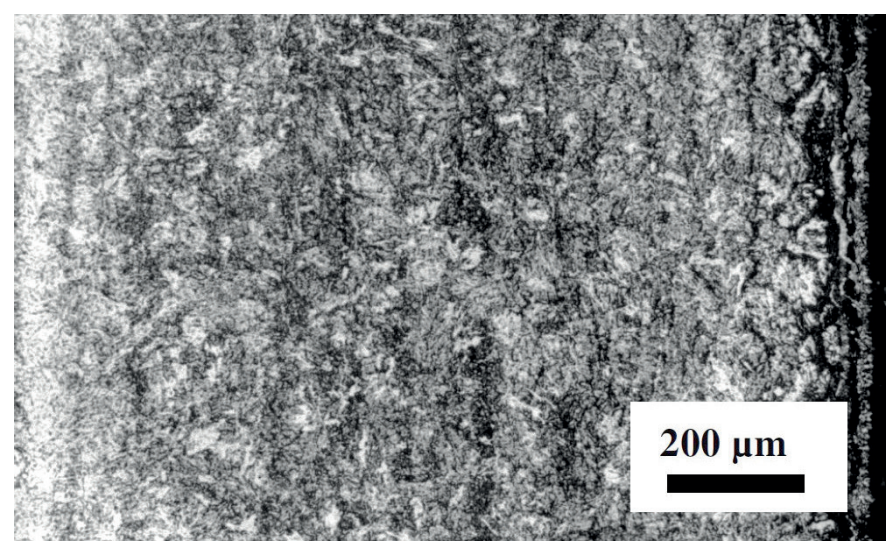

Fig. 6. The microstructure of nitrided layers of oxygen diffusion 
nitriding process, or with $\mathrm{H}_{2}+\mathrm{NB}+$ air (about 4\%) - oxygen and nitriding process;

- fully adjustable phases of composition of layers with different thickness zones of iron, both with and without the compounds zone. The surface layers are of varying diffusion state of residual stress, depending on the process and type of layers formed. There are compressive stresses $[2,7]$;

- eliminating the need to grind (the plasma discharge nitriding process is a finishing treatment);

- the ability to thread complex shape parts.

The advantages of the plasma nitriding processes allow for the formation of layers with optimal characteristics in terms of their specific applications. Forming the structure, chemical composition, and thickness of the individual zones of the layer has an impact on the internal stress of the layer, and thus the useful properties.

\section{Production of wear-resistant composite layers on the surface of piston rings}

The research was designed for the production of wear-resistant composite layers on the surface of piston rings in a piston aircraft engine with a previously-prepared chromium plating film, using the process of nitriding. The study was conducted on piston rings made of cast iron and electrochemically coated with chromium, with a thickness of $150 \mu \mathrm{m}$, and a ring made of H12MF steel, also with a chromium coating and the same thickness. The plasma nitriding process was carried out twice, lasting for $6 \mathrm{~h}$ and $12 \mathrm{~h}$. The pressure in the reactive mixture in the working chamber for the two trials was different, and as follows: $2 \mathrm{hPa}$ or $4 \mathrm{hPa}$. Also, before the nitriding process, cathode sputtering in argon and hydrogen was applied. The temperature of the plasma nitriding was in the range of $480-560^{\circ} \mathrm{C}$.

The study employed a sample of the materials used for the production of piston rings provided by the engine manufacturer, i.e.:

- ductile cast iron special S-13 (chemical composition: $\mathrm{C}-3.5 \div 4.00, \mathrm{Si}-2.1 \div 3.3, \mathrm{Mn}-0.2 \div 0.5, \mathrm{P}-0.3$, $\mathrm{S} \leq 0.05, \mathrm{Cr} \leq 0.2, \mathrm{Cu} \leq 1.0)$;

- martensitic stainless chrome-plated DIN 1.4112, ASL 817 (chemical composition: $\mathrm{C}-0.8 \div 0.9, \mathrm{Si}-0.15 \div 0.30$, $\mathrm{Mn}-0.25 \div 0.4, \mathrm{P}-0.040, \mathrm{~S}-0.030, \mathrm{Cr}-17 \div 18$, Mo $-1.0 \div 1.25, \mathrm{~V}-0.08 \div 0.15)$

A study of surface microstructure revealed the presence of cracks in the chromium coatings produced on the rings (Figs. 7-9). Visible on the surface of the coating, the cracks were formed by changing the polarity of the electric current in the final stage of the galvanic process. Fig. 7 shows the socalled "dense" network of cracks that formed during the electrochemical application of chromium to ductile iron rings. Fig. 8 shows the so-called "dense" grid cracks resulting from the application of chromium to H12MF steel ring, and Fig. 9shows the so-called "large" net cracks.

The presented research shows that a grid of cracks in the chromium coating has a significant impact on the surface. The

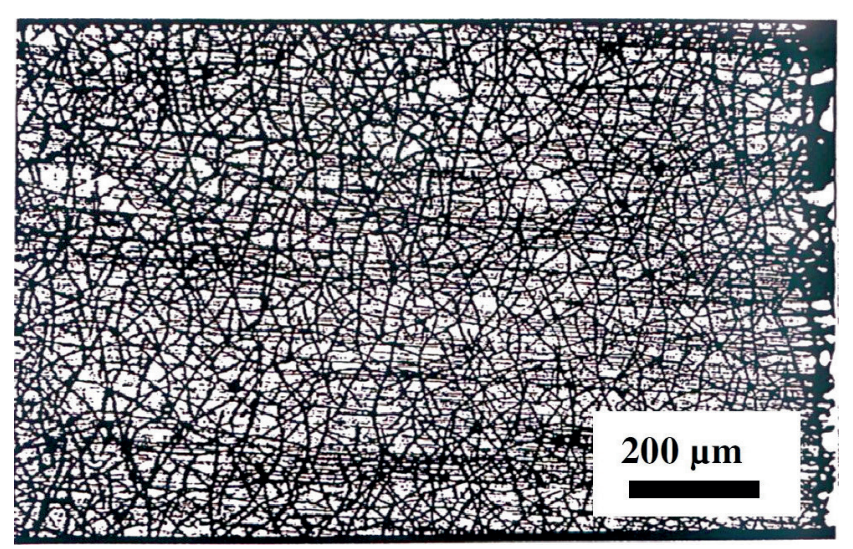

Fig. 7. Grid cracks on the surface of the chromium coating on a ring made of ductile iron

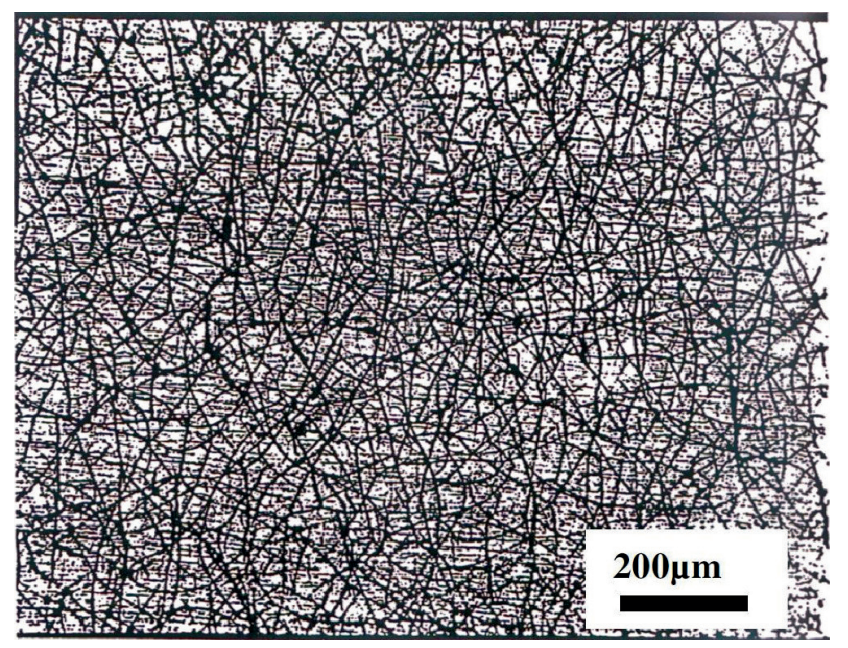

Fig. 8. Grid cracks on the surface of the chromium coating on a H12MF steel ring

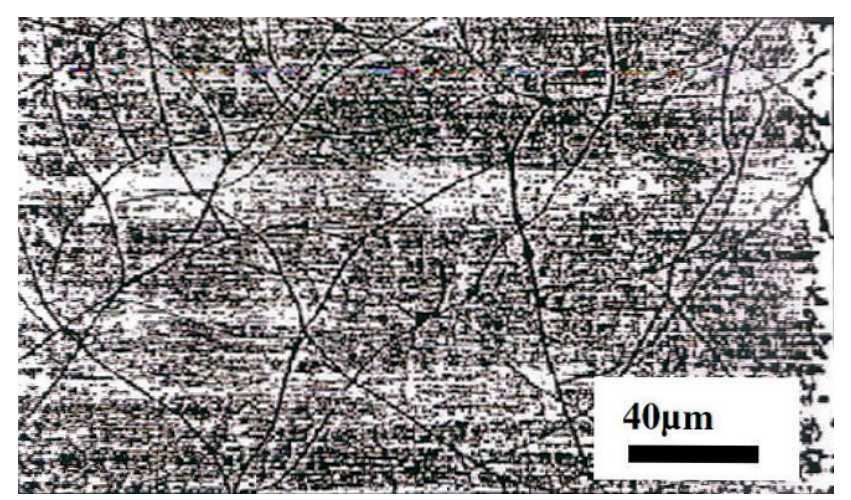

Fig. 9. Grid cracks on the surface of the chromium coating on a H12MF steel ring (zoom)

fractures in chromium coating of iron occur in greater quantities. Grid cracks on the piston rings play an important role in the exploitation (oil micro-reservoirs), as well as in the plasma nitriding process. 


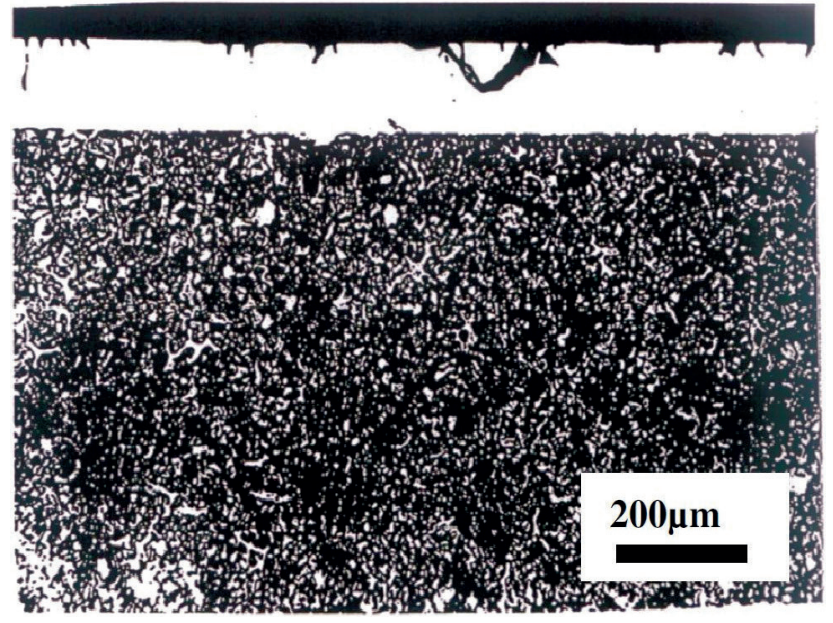

Fig. 10. The microstructure layer of chrome - a large network of cracks (transverse metallographic section) on a ring made of ductile iron

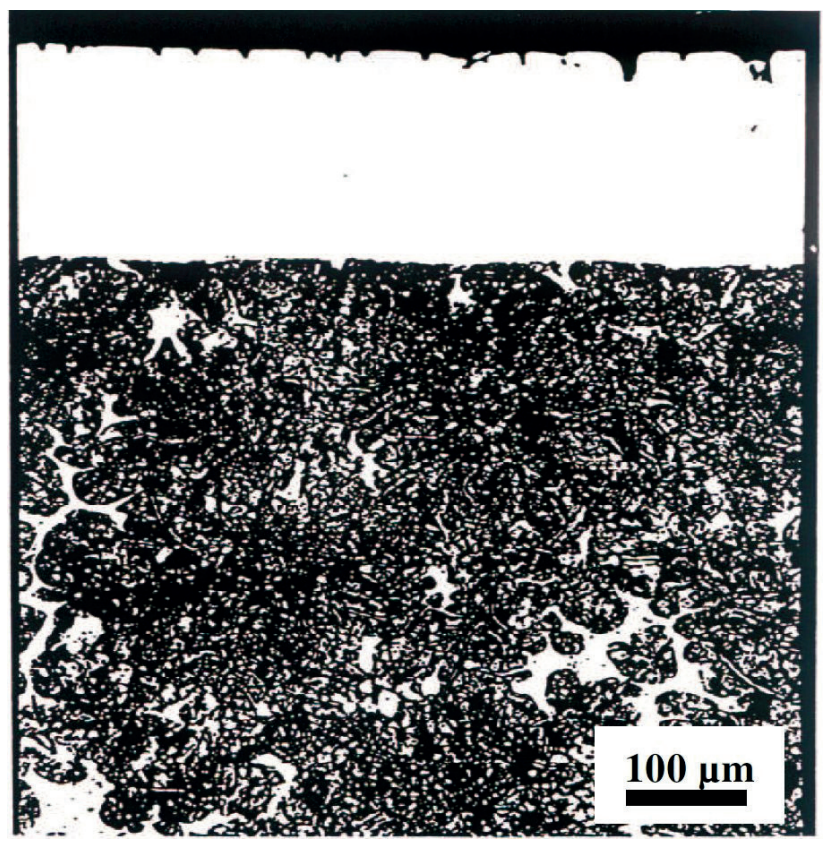

Fig. 11. The microstructure of chrome layers - a dense network of cracks (transverse metallographic section) on a ring made of ductile iron

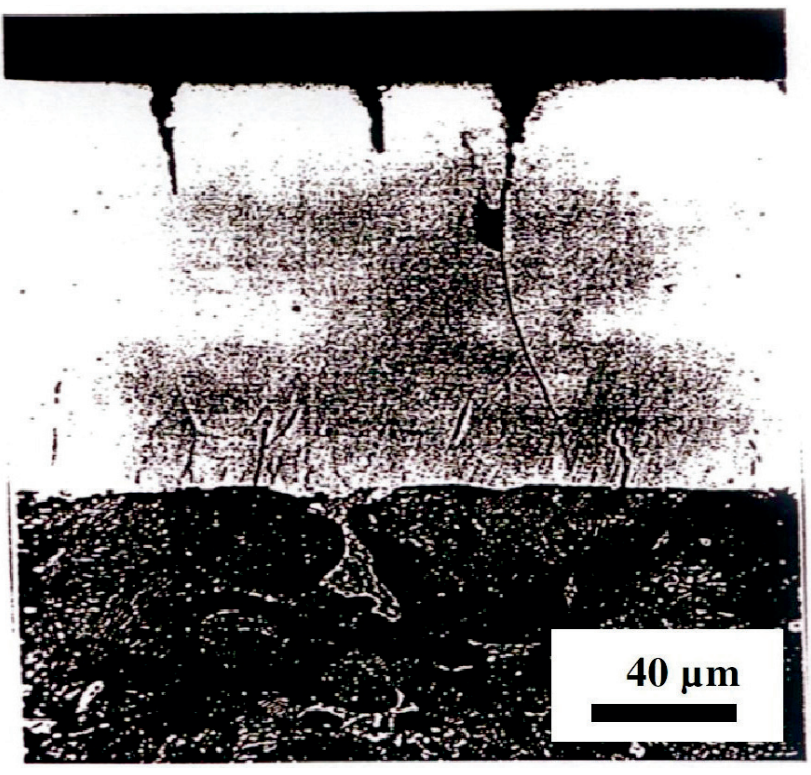

Fig. 12. The microstructure layer of chromium - a large network of cracks (transverse metallographic section) on a ring made of ductileiron

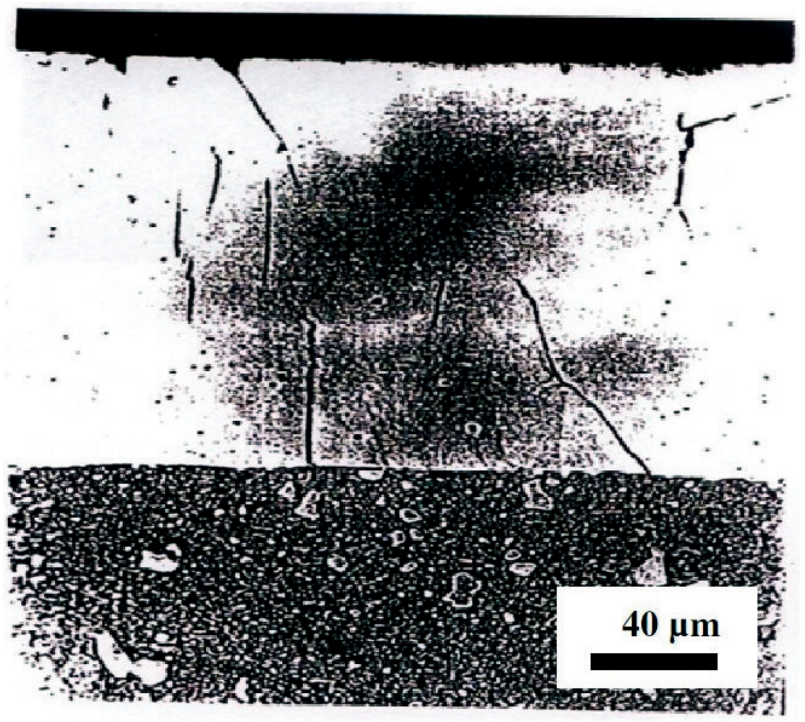

Fig. 13. The microstructure of the chromium layer - a large network of cracks (transverse metallographic section) on a H12MF steel ring
The study of microstructure chromium coatings (Figs. 10-13) was performed on transverse metallographic sections after etching it with Keller reagent with the following chemical composition: $0.5 \mathrm{~cm}^{3} \mathrm{HF}+99.5 \mathrm{~cm}^{3} \mathrm{H}_{2} 0$.

The number of cracks inside the chromium shell of H12MF steel is clearly greater than in the coating on nodular cast iron, despite the fact that this layer has "dense" grid cracks on the surface. Cracks come from within the coating to the substrate.

The ductile iron and H12MF steel rings coated with chromium were subjected to plasma nitriding processes. Processing parameters are listed in Table 1.
Table 1

Parameters of plasma nitriding chromium coatings processes

\begin{tabular}{|c|c|c|c|c|}
\hline $\begin{array}{c}\text { Process } \\
\text { No }\end{array}$ & $\begin{array}{c}\text { Temperature } \\
{\left[{ }^{\circ} \mathrm{C}\right]}\end{array}$ & $\begin{array}{c}\text { Pressure } \\
{[\mathrm{hPa}]}\end{array}$ & $\begin{array}{c}\text { Time } \\
{[\mathrm{h}]}\end{array}$ & $\begin{array}{c}\text { The composition of } \\
\text { the gas mixture }\end{array}$ \\
\hline 1 & 560 & 2 & 6 & $\mathrm{H}_{2}+\mathrm{N}_{2}$ \\
\hline 2 & 480 & 2 & 6 & $\mathrm{H}_{2}+\mathrm{N}_{2}$ \\
\hline 3 & 480 & 4 & 12 & $\mathrm{H}_{2}+\mathrm{N}_{2}$ \\
\hline 4 & 560 & 4 & 12 & $\mathrm{H}_{2}+\mathrm{N}_{2}$ \\
\hline
\end{tabular}


Figure 14 shows an example of the microstructure of the composite layer type $\mathrm{Cr} 2 \mathrm{~N}+\mathrm{CrN}+\mathrm{Cr}+(\mathrm{CrFe})_{7} \mathrm{C}_{3}$, received on the surface of ductile iron with the so-called "dense" grid cracks. The microstructures presented, made of composite layers, shows that the thickness of the chromium nitride $\mathrm{CrN}$ and $\mathrm{Cr}_{2} \mathrm{~N}$ in the outer zone of the composite layer in process No. 1 is thinner (about $6 \mu \mathrm{m}$ ) than in process No. 4 (about $16 \mu \mathrm{m}$ ). This is due to the increase of the duration of the plasma nitriding process. The study of micro-hardness HV0.05 after plasma nitriding showed that the chromium nitride layer with the highest hardness of the surface (approximately $1800 \mathrm{HV} 0.05$ ) was obtained in process No. 4 at a temperature of $560^{\circ} \mathrm{C}$ for 12 hours, while in the process No. 1 , at a temperature of $560^{\circ} \mathrm{C}$ for 6 hours, the obtained surface hardness was $1650 \mathrm{HV} 0.05$. a)

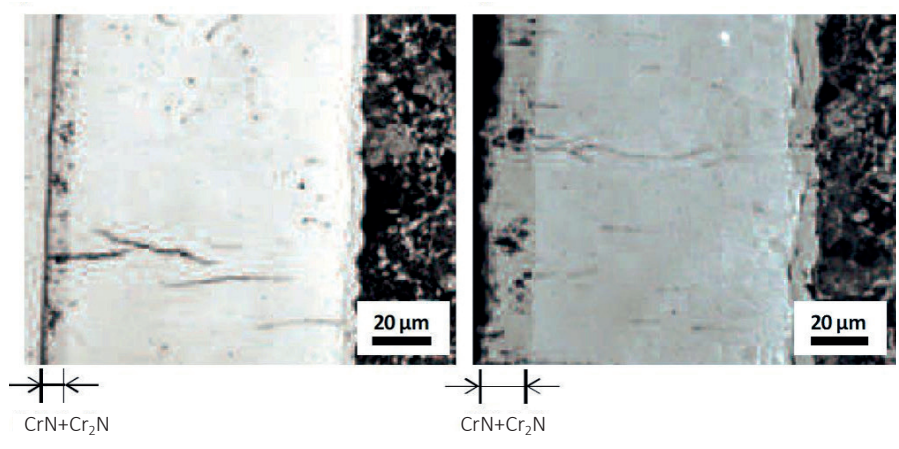

Fig. 14. The microstructure of the composite layer type $\mathrm{CrN}+\mathrm{Cr}_{2} \mathrm{~N}+$ $+\mathrm{Cr}+(\mathrm{CrFe})_{7} \mathrm{C}_{3}$, produced in the process of plasma nitriding of chromium coating on ductile iron: a) process No. 1, b) process No. 4 , (Table 1)

For processes No. 2 and No. 3, the surface hardness was $1350 \mathrm{HV} 0.05$ due to the formation of a thin layer of chromium nitrides with a thickness of about 1.5-2 $\mu \mathrm{m}$. The hardness of the chromium layer in both cases was $1100 \mathrm{HV} 0.05$. Exemplary distributions of micro-hardness received in the composite layers produced in processes No. 1 and No. 4 are shown in Fig. 15.

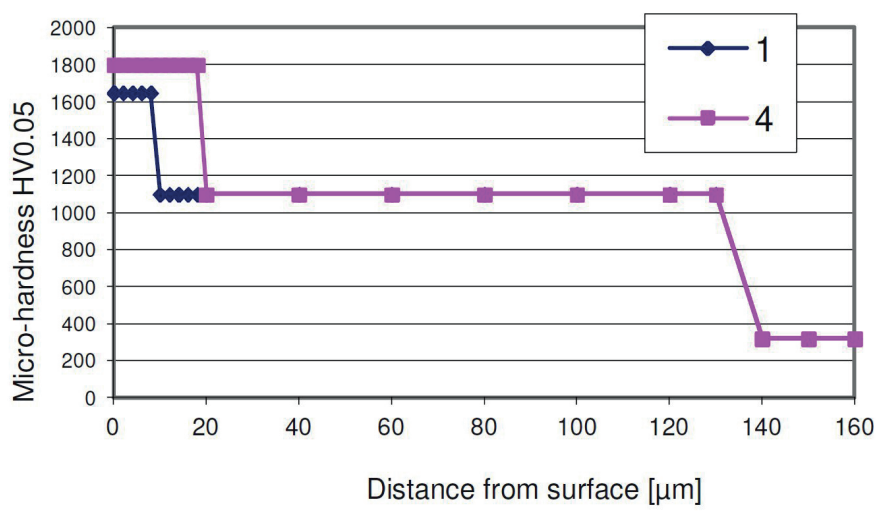

Fig. 15. Micro-hardness profiles in the composite layers produced in processes No. 1 and No. 4
The study leads to the following conclusions and observations:

1. Plasma nitriding of chromium coatings on the piston rings of cast-iron and steel surface can generate chromium nitride $-\mathrm{CrN}$ and $\mathrm{Cr}_{2} \mathrm{~N}$ with a hardness of about 1650-1800 HV0.05. The surface hardness of the chrome coating was 1100 HV0.05.

2. The most preferred parameters of the nitriding process in both rings of cast iron and steel are process temperature $\left(560{ }^{\circ} \mathrm{C}\right)$, duration of the nitriding process $(6-12 \mathrm{~h}$, depending on the thickness of the area of chromium nitrides) and pressure in the working chamber $(4 \mathrm{hPa})$.

3. Surface diffusion layer of chromium nitride, as shown by our previous study $[5,6]$, has a significant effect on the increase of resistance to frictional wear and corrosion of the treated materials.

4. The plasma nitriding process ensures the elimination of distortion of the rings and preserves the structure of the substrate, and thus its strength properties.

\section{Research of friction couples of cylinder liners - piston rings with an anti-wear layer formed in the laboratory using the method of isotopic markers}

The testing was conducted in a reciprocating movement, thoroughly modernizing the existing test bench. As part of the modernization of the bench for testing samples for friction and wear in a reciprocating motion, the following were designed and manufactured:

- head for clamping ring samples,

- drip lubrication system with automatic adjusting and supervision of oil flow,

- heating system for samples with adjustable friction and temperature stability,

- new set of bearings.

The test bench consists of:

1. A drive system with a gear-reducing belt,

2. A crank system,

3. A movable holder for mounting the samples of the cylinder liner,

4. Head for mounting the ring samples,

5. The body with the head and the loading arrangement,

6. Drip lubrication system with automatic adjusting and supervision of oil flow,

7. Heating system for samples, with adjustable friction and temperature stability,

8. Vibration-insulated base.

Proper emphasis is achieved by a system of blocks and weights clamping the head with the ring to the handle with the sample cylinder liner that executes the reciprocating motion. Speed control is achieved by changing the pulleys and the speed of the electric engine. The stroke is controlled in a crank system. A schematic of the measuring system is shown in Fig. 16, and of the adjustable heating system in Fig. 17. 


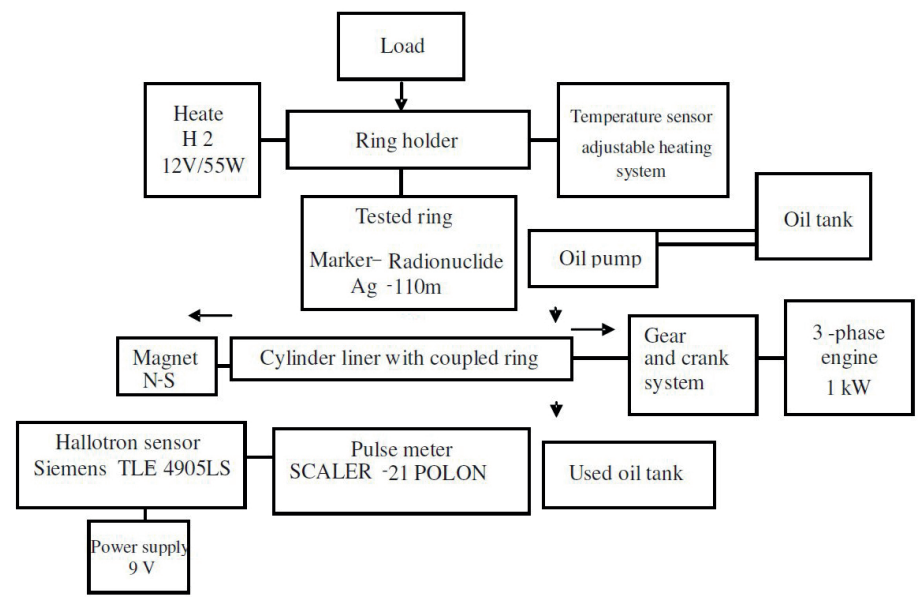

Fig. 16. Block diagram of the test bench for measuring the consumption of a band ring - cylinder liner

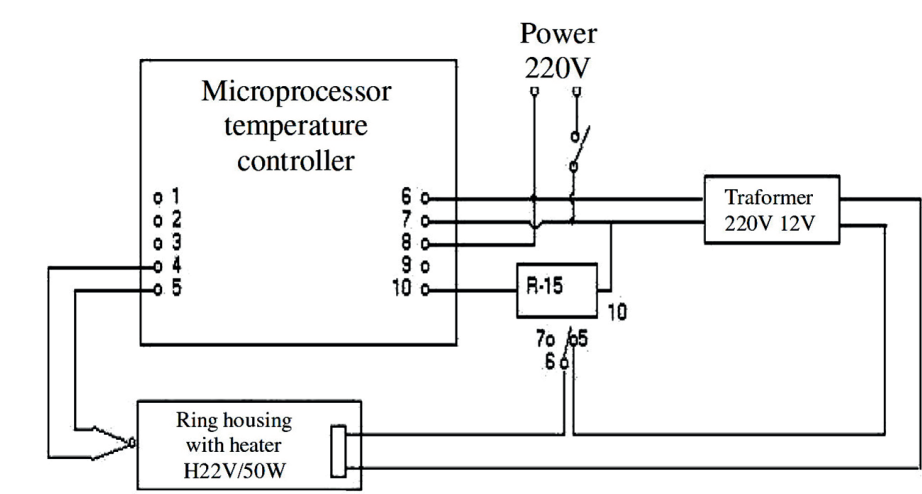

Termocouple Fe-Konstantan GE483

Fig. 17. Schematic of the adjustable heating system

The study used radioactive isotopes to compare the degree of wear on the rings made by the manufacturer of the engine and modified by the employees of the Warsaw University of Technology $[9,10]$. Radionuclide $\mathrm{Ag}^{110 \mathrm{~m}}$ was introduced into the ring as an insert (Fig. 18). In the ring, a hole with a diameter of about $0.95 \mathrm{~mm}$ and a depth of $0.8 \mathrm{~mm}$ was drilled. In this hole, a cylinder made out of active silver $\left(\mathrm{Ag}^{110 \mathrm{~m}}\right)$ with a diameter $\varphi 0.95 \mathrm{~mm}$ and a length of $1 \mathrm{~mm}$ was inserted (Fig. 18). To protect the insert from falling, QUICK METAL glue was applied, which tied the two elements. The setting time was shortened by heating the glued elements to a temperature of $60^{\circ} \mathrm{C}$ for $6 \mathrm{~h}$. The prepared working sample of the ring and cylinder liner was subjected to reciprocating movement on a bench. A block diagram of the bench is shown in Fig. 16. Measurement and regulation of the temperature on the surface of the ring were performed with a device constructed according to the scheme shown in Fig. 17.

The process of friction for each cycle lasted:

$1^{\text {st }}$ cycle -15 minutes with a ring loaded for $54 \mathrm{~N}$

$2^{\text {nd }}$ cycle -60 minutes with a ring loaded for $105 \mathrm{~N}$

$3^{\text {rd }}$ cycle -120 minutes with a ring loaded for $132 \mathrm{~N}$ (until the end of the friction process)
During the first cycle, the surface of the insert was leveled relative to the ring. The measuring point was not taken into account in further calculations.

The device was equipped with a counter of the number of strokes. The path of one stroke was $0.06 \mathrm{~m}$. The path traveled by the cylinder liner on the ring is the sum of previous and current cycles.

Radionuclide $\mathrm{Ag}^{110 \mathrm{~m}}$ was obtained by activating metallic silver in the MARIA reactor. Thermal neutron flux was $5^{*} 10^{13} \mathrm{n} / \mathrm{cm}^{2} / \mathrm{s}$, the time of activation was $7 \mathrm{~h}$, and the mass of the insert was about $0.01 \mathrm{~g}$.

Measurement of the intensity of radiation was conducted with HP detector produced by Ortec, which collaborated with a type S100 spectrometer produced by Canberra System, controlled using an IBM computer. This high-spectrometric system was used to exclude the impact of radiation emitted by any silver impurities.

Radionuclide $\mathrm{Ag}^{110 \mathrm{~m}}$ emits gamma radiation with an energy level of $658 \mathrm{keV}$ (with probability of $100 \%), 885 \mathrm{keV}(42 \%)$, $764 \mathrm{keV}$ (18\%), $937 \mathrm{keV}(18 \%), 706 \mathrm{keV}$ (13\%) and some energy with a low probability. The probability of radiation with an energy level of $658 \mathrm{keV}$ was the highest, but because of the potential disruption caused by $\mathrm{Cs}^{137}$ (which emits radiation with an energy level of $661 \mathrm{keV}$ ), the energy level of $885 \mathrm{keV}$ was adopted for the calculation. After each abrasion cycle, the ring was measured three times. The average of these measurements is shown in the column of radiation intensities in Tables 2-5 $[2,9]$. The resulting radiation intensity measurements, lasting 7-10 days for each series, were brought to zero time to exclude the decrease in radiation due to the degradation of $\mathrm{Ag}^{110 \mathrm{~m}}$ (half-life of 253 days). The results are provided in Tables 2-5, column No. 4 (radiation intensity at hour "00”). These measurement results were subjected to statistical processing. Regression was determined by describing a probable relationship between radiation intensity and distance traveled by rings on the cylinder liner. These relationships are illustrated in Tables 2-5 and Figs. 18-21. From the equations describing the straight line placed in Figs. 18-21, the wear of rings at the distance of $100 \mathrm{~km}$ was determined. Wear in this case is described as a decrease in radiation intensity (expressed in counts per minute), which results from the friction of the ring with the insert mounted moving along the surface of the cylinder liner.

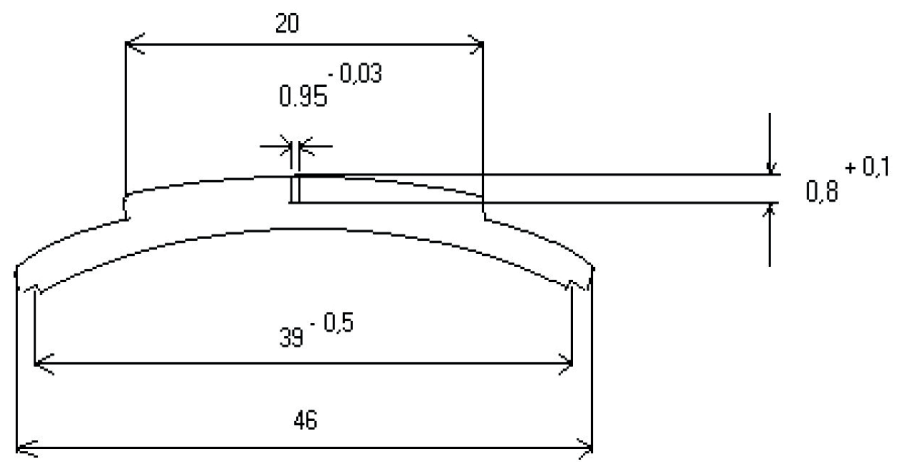

Fig. 18. Ring with a hole dedicated for the isotopic insert 
Table 2

The basic results of wear of rings in $1 \mathrm{~W} 1-1$ couple

\begin{tabular}{|c|c|c|c|c|}
\hline \multicolumn{5}{|c|}{ The results of measurements of friction couple: 1W1-1 } \\
\hline $\begin{array}{c}\text { Distance } \\
{[\mathrm{m}]}\end{array}$ & $\begin{array}{c}\text { Radiation } \\
\text { Intensity } \\
\text { [counts/min] }\end{array}$ & $\begin{array}{c}\text { Cooling } \\
\text { Time } \\
\text { [days] }\end{array}$ & $\begin{array}{c}\text { Radiation intensity } \\
\text { at hour “00" } \\
\text { [counts/min] }\end{array}$ & Cycle \\
\hline 5546 & 80098 & 60.03 & 94416 & 1 \\
\hline 14422 & 77875 & 60.15 & 91825 & 2 \\
\hline 27738 & 76531 & 63.06 & 90964 & 3 \\
\hline 41055 & 76241 & 63.23 & 90661 & 4 \\
\hline 54359 & 76735 & 63.97 & 91434 & 5 \\
\hline 67677 & 77013 & 64.15 & 91809 & 6 \\
\hline 80996 & 76596 & 64.98 & 91521 & 7 \\
\hline 94318 & 76867 & 65.13 & 91882 & 8 \\
\hline 107642 & 76799 & 65.27 & 91837 & 9 \\
\hline 120958 & 76628 & 65.98 & 91810 & 10 \\
\hline 134296 & 76580 & 66.13 & 91791 & 11 \\
\hline 147622 & 76479 & 66.30 & 91711 & 12 \\
\hline 161030 & 76331 & 67.03 & 91719 & 13 \\
\hline
\end{tabular}

Per the terms of the study, a load delivering pressure of 2.3 $\mathrm{MPa}[13,5 \mathrm{~kg} /(20 \mathrm{~mm} * 2,9 \mathrm{~mm})]$, the average linear speed of slider $\mathrm{v}=1.3 \mathrm{~m} / \mathrm{s}$, and slider stroke of $60 \mathrm{~mm}$ was assumed. Ring temperature was $\mathrm{t}=110^{\circ} \mathrm{C}$. Lubrication drip was 1 drop per minute. Research results for the three best and worst friction couples are shown in Tables 2-5 and Figs. 19-22.

The conditions of the samples are more difficult than those in a real engine, assuming its correct functioning without any significant "nosing" of the piston. In a working ASz-62IR engine, the average speed is an order of magnitude greater, and the pressure on the ring is several times smaller. The amount of grease is also higher. hus, tribological conditions are better in the engine than on the bench.

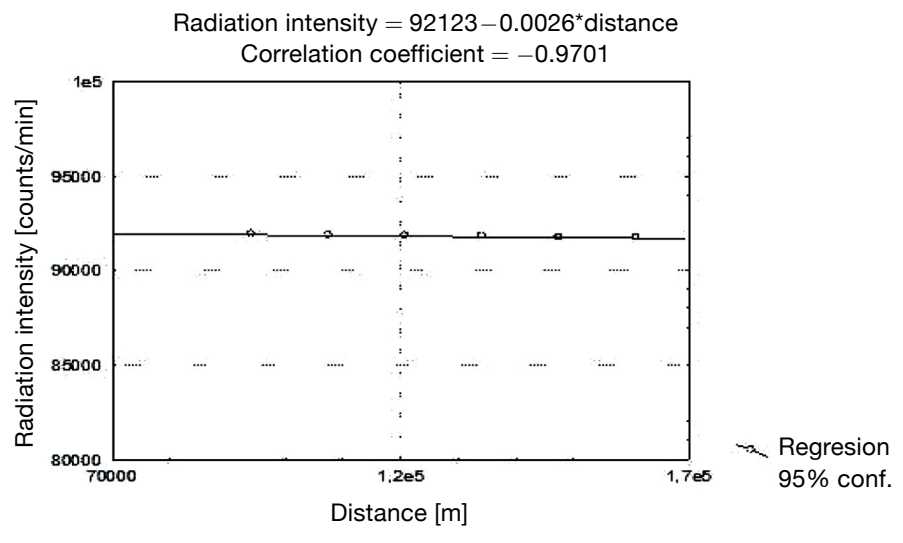

Fig. 19. Wear of ring as a function of distance $-1 \mathrm{~W} 1-1$ couple (actual screenshot, vertical axis represents radiation intensity [counts/min], horizontal axis represents distance $[\mathrm{m}]$ )
Table 3

The basic results of wear of rings in OPI-PO1 couple

\begin{tabular}{|c|c|c|c|c|}
\hline \multicolumn{5}{|c|}{ The results of measurements of friction couple OPI-PO1 } \\
\hline $\begin{array}{c}\text { Distance } \\
\text { [m] }\end{array}$ & $\begin{array}{c}\text { Radiation } \\
\text { Intensity } \\
\text { [counts/min] }\end{array}$ & $\begin{array}{c}\text { Cooling } \\
\text { time } \\
\text { [days] }\end{array}$ & $\begin{array}{c}\text { Radiation intensity } \\
\text { at hour “00” } \\
\text { [counts/min] }\end{array}$ & Cycle \\
\hline 1127 & 111102 & 36.92 & 122927 & 1 \\
\hline 5602 & 110073 & 37.00 & 121816 & 2 \\
\hline 14487 & 92632 & 37.15 & 102558 & 3 \\
\hline 23366 & 95474 & 37.27 & 105739 & 4 \\
\hline 32250 & 95723 & 37.39 & 106049 & 5 \\
\hline 41132 & 93784 & 37.94 & 104058 & 6 \\
\hline 50012 & 86106 & 38.07 & 95571 & 7 \\
\hline 58892 & 92111 & 38.18 & 102268 & 8 \\
\hline 67773 & 94552 & 38.32 & 105017 & 9 \\
\hline 76656 & 95436 & 38.32 & 105999 & 10 \\
\hline 85533 & 95330 & 39.06 & 106098 & 11 \\
\hline 94411 & 95274 & 39.06 & 106036 & 12 \\
\hline 103292 & 94626 & 42.02 & 106172 & 13 \\
\hline 112176 & 94073 & 42.15 & 105588 & 14 \\
\hline 121041 & 94285 & 42.27 & 105862 & 15 \\
\hline 129919 & 92087 & 43.02 & 103606 & 16 \\
\hline 138801 & 94126 & 43.14 & 105936 & 17 \\
\hline 147686 & 94260 & 43.28 & 106126 & 18 \\
\hline 156572 & 93416 & 44.03 & 105392 & 19 \\
\hline 165470 & 93473 & 44.15 & 105492 & 20 \\
\hline 174353 & 93843 & 45.03 & 106164 & 21 \\
\hline 183235 & 94155 & 45.17 & 106559 & 22 \\
\hline 192116 & 92698 & 46.03 & 105158 & 23 \\
\hline 201000 & 92693 & 46.16 & 105189 & 24 \\
\hline 209881 & 93047 & 49.02 & 106422 & 25 \\
\hline 208768 & 92138 & 49.18 & 105427 & 26 \\
\hline & & & & \\
\hline
\end{tabular}

To determine the regression line shown in Fig. 20, the first two results in Table 2 were rejected. To determine the regression line shown in Fig. 21, the first results in Table 3 were rejected. The regression line and the correlation coefficient were estimated in Figs. 20-23, based on the results in columns 1 and 4 in Tables 1-5.

The lapping time of samples was about 5-7 h, assuming full adherence of the sample ring to the curvature of the sample cylinder liner. For the first baseline sample, a 200-hour testing process was carried out, until the process marked an increase in wear (second inflection of the Lorenz curve). For the remaining samples, research was conducted in 40-hour periods of time to obtain several (eight) data points at which the intensity of radiation was examined. This was enough to determine the tangent of the pitch angle of the wear line, which is a reference measure in the wear tests using a radiation tracer. Based on the results of 
Table 4

The basic results of wear of rings in 1 WII-2 couple

\begin{tabular}{|c|c|c|c|c|}
\hline \multicolumn{5}{|c|}{ The results of measurements of friction couple 1WII-2 } \\
\hline $\begin{array}{c}\text { Distance } \\
{[\mathrm{m}]}\end{array}$ & $\begin{array}{c}\text { Radiation } \\
\text { Intensity } \\
\text { [counts/min] }\end{array}$ & $\begin{array}{c}\text { Cooling } \\
\text { time } \\
\text { [days] }\end{array}$ & $\begin{array}{c}\text { Radiation intensity } \\
\text { at hour “00” } \\
\text { [counts/min] }\end{array}$ & Cycle \\
\hline 1206 & 84075 & 72.94 & 102672 & 1 \\
\hline 5642 & 81873 & 73.02 & 100006 & 2 \\
\hline 18969 & 80972 & 73.17 & 98944 & 3 \\
\hline 32295 & 80856 & 74.02 & 99034 & 4 \\
\hline 45717 & 80780 & 74.17 & 98981 & 5 \\
\hline 59042 & 80482 & 77.04 & 99395 & 6 \\
\hline 67928 & 80254 & 77.16 & 99146 & 7 \\
\hline 76795 & 80352 & 77.28 & 99301 & 8 \\
\hline 90114 & 79752 & 78.03 & 98762 & 9 \\
\hline 98997 & 79858 & 78.16 & 98926 & 10 \\
\hline 112327 & 79228 & 79.98 & 98637 & 11 \\
\hline 125657 & 79249 & 80.13 & 98703 & 12 \\
\hline 138993 & 79596 & 80.28 & 99178 & 13 \\
\hline 152323 & 79044 & 80.98 & 98678 & 14 \\
\hline
\end{tabular}

Table 5

The basic results of wear of rings in OK1-OK2 couple

\begin{tabular}{|c|c|c|c|c|}
\hline \multicolumn{5}{|c|}{ The results of measurements of friction couple 1WII-2 } \\
\hline $\begin{array}{c}\text { Distance } \\
\text { [m] }\end{array}$ & $\begin{array}{c}\text { Radiation } \\
\text { Intensity } \\
\text { [counts/min] }\end{array}$ & $\begin{array}{c}\text { Cooling } \\
\text { time } \\
\text { [days] }\end{array}$ & $\begin{array}{c}\text { Radiation intensity } \\
\text { at hour “00” } \\
\text { [counts/min] }\end{array}$ & Cycle \\
\hline 1107 & 105354 & 14.16 & 109521 & 1 \\
\hline 5541 & 104853 & 14.25 & 109028 & 2 \\
\hline 14416 & 104944 & 14.35 & 109153 & 3 \\
\hline 23288 & 103584 & 15.02 & 107936 & 4 \\
\hline 32160 & 104696 & 15.14 & 109131 & 5 \\
\hline 41035 & 104452 & 15.26 & 108911 & 6 \\
\hline 49914 & 104452 & 15.38 & 108946 & 7 \\
\hline 58784 & 102748 & 15.95 & 107337 & 8 \\
\hline 67662 & 103730 & 16.07 & 108398 & 9 \\
\hline 76549 & 104066 & 16.19 & 108785 & 10 \\
\hline 85429 & 103606 & 20.95 & 109727 & 11 \\
\hline 94299 & 103426 & 21.07 & 109572 & 12 \\
\hline 103169 & 103897 & 21.18 & 110105 & 13 \\
\hline 112045 & 102165 & 25.17 & 109460 & 14 \\
\hline 120921 & 101846 & 27.98 & 109961 & 15 \\
\hline 129793 & 101972 & 28.10 & 110133 & 16 \\
\hline 138660 & 101918 & 28.22 & 110110 & 17 \\
\hline
\end{tabular}

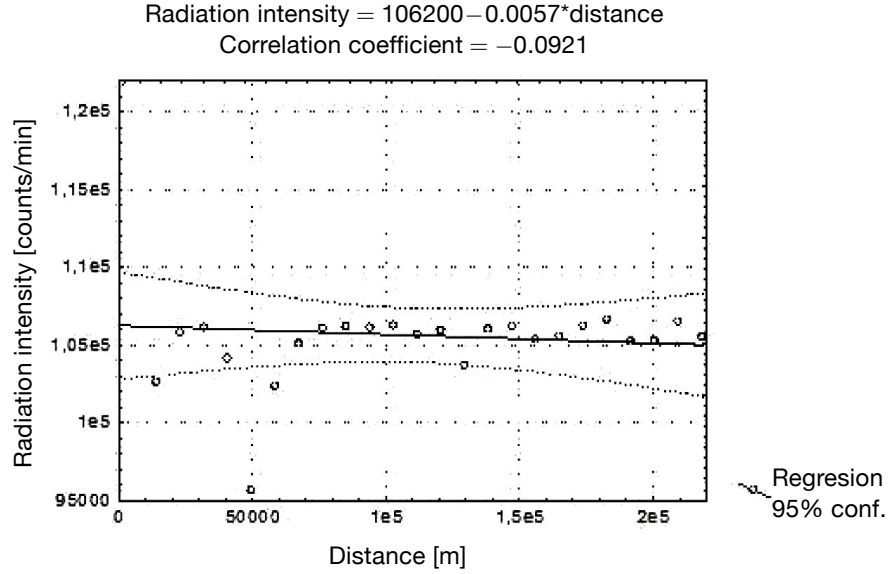

Fig. 20. Wear of ring as a function of distance-OPI-PO1 couple (actual screenshot, vertical axis represents radiation intensity [counts/min], horizontal axis represents distance $[\mathrm{m}]$ )

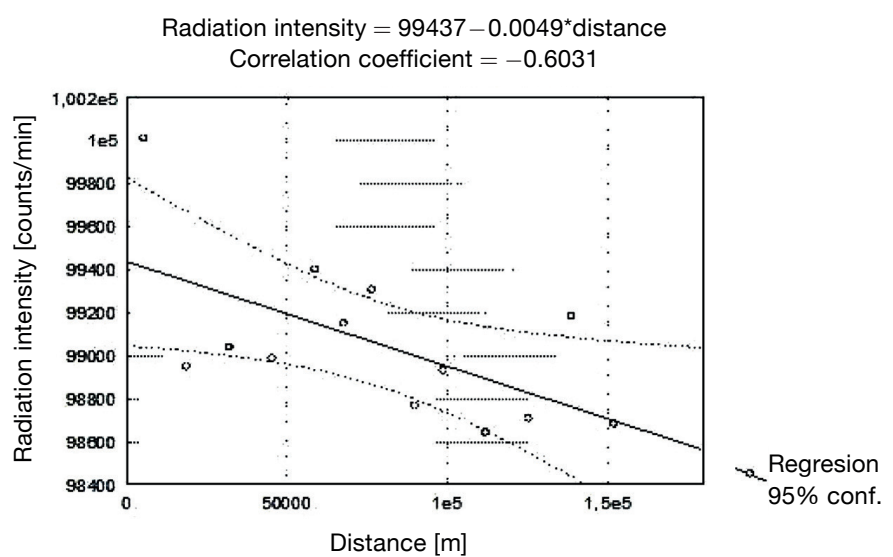

Fig. 21. Wear of ring as a function of distance - 1WII-2 couple (actual screenshot, vertical axis represents radiation intensity [counts/min], horizontal axis represents distance $[\mathrm{m}]$ )

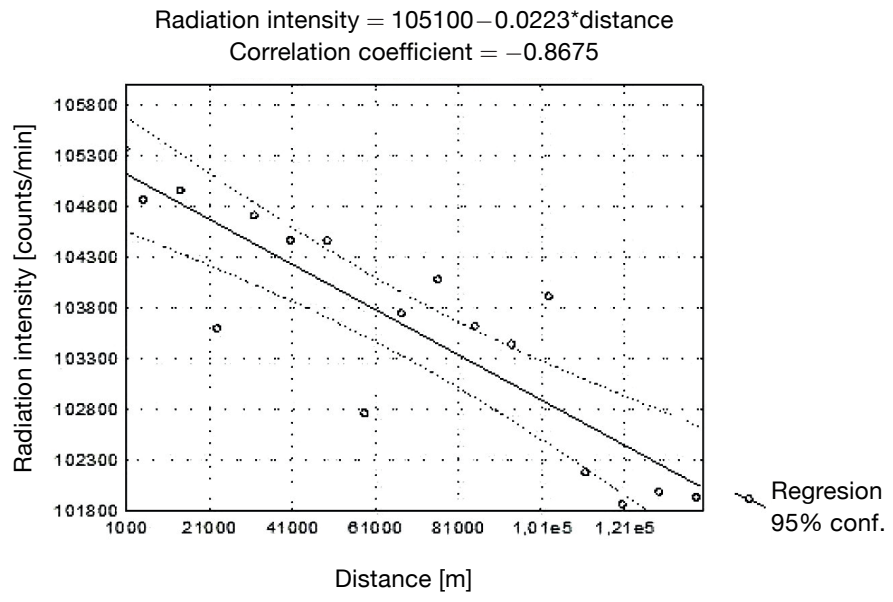

Fig. 22. Wear of ring as a function of distance-OK1-OK2 couple (actual screenshot, vertical axis represents radiation intensity [counts/min], horizontal axis represents distance $[\mathrm{m}]$ ) 


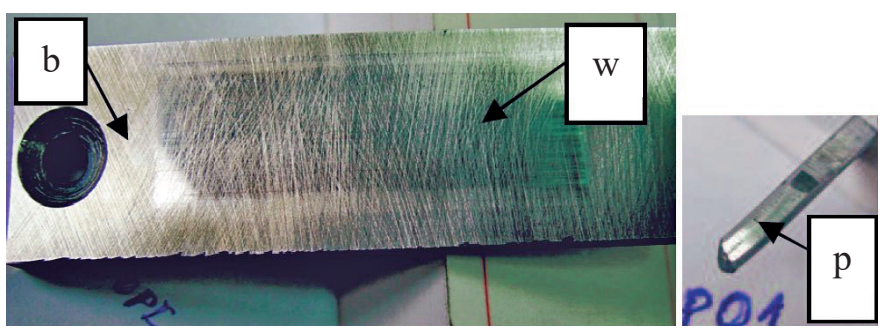

Fig. 23. Traces of cooperation of friction couple OP1-PO1

the full study, whose sample results are shown in Tables 2-5 and in graphs showing the regression lines in Figs. 19-22, a summary table was prepared, presenting ring wear in arbitrary units (higher value means proportionately greater wear of the ring as a function of distance traveled for each sliding couple), delivered in Tables 6 and 7.

Table 6

Summary results of wear of rings in arbitrary units

\begin{tabular}{|c|c|c|c|}
\hline $\begin{array}{c}\text { Friction } \\
\text { couples }\end{array}$ & $\begin{array}{c}\text { Ring } \\
\text { symbol }\end{array}$ & $\begin{array}{c}\text { Distance } \\
{[\mathrm{km}]}\end{array}$ & $\begin{array}{c}\text { Wear of rings } \\
{[\text { arbitrary units }]}\end{array}$ \\
\hline $1 \mathrm{~K}-02$ & O2 & 255.8 & 2230 \\
\hline OK1 - OK2 & OK2 & 138.7 & 1660 \\
\hline IP1 - IP1 & IP1 & 138.7 & 1330 \\
\hline OPI - PO1 & PO1 & 208.8 & 570 \\
\hline OPII - PO2 & PO2 & 168.9 & 0 \\
\hline $1 \mathrm{WI}-1$ & 1 & 161.0 & 260 \\
\hline $2 \mathrm{WI}-5$ & 5 & 125.6 & 1910 \\
\hline $1 \mathrm{WII}-2$ & 2 & 152.3 & 490 \\
\hline $2 \mathrm{WII}-3$ & 3 & 174.8 & 0 \\
\hline
\end{tabular}

Table 7

The results of the wear of rings per kilometer of distance traveled.

\begin{tabular}{|c|c|c|c|c|}
\hline $\begin{array}{c}\text { Friction } \\
\text { couples }\end{array}$ & $\begin{array}{c}\text { Ring } \\
\text { symbol }\end{array}$ & $\begin{array}{c}\text { Distance } \\
{[\mathrm{km}]}\end{array}$ & $\begin{array}{c}\text { Wear of } \\
\text { rings } \\
\text { arbitrary } \\
\text { units/km }]\end{array}$ & $\begin{array}{c}\text { The order } \\
\text { according to } \\
\text { minimum wear } \\
\text { of ring }\end{array}$ \\
\hline $1 \mathrm{~K}-02$ & O2 & 255.8 & 8.71 & 6 \\
\hline OK1 - OK1 & OK1 & 138.7 & 11.94 & 8 \\
\hline IP1 - IP1 & IP1 & 138.7 & 9.59 & 7 \\
\hline OP1 - PO1 & PO1 & 208.8 & 2.72 & 4 \\
\hline OP2 - PO2 & PO2 & 168.9 & 0 & 2 \\
\hline $1 \mathrm{WI}-1$ & 1 & 161.0 & 1.61 & 3 \\
\hline $2 \mathrm{WI}-5$ & 5 & 125.6 & 15.28 & 9 \\
\hline $1 \mathrm{WII}-2$ & 2 & 152.3 & 3.22 & 5 \\
\hline $2 \mathrm{WII}-3$ & 3 & 174.8 & 0 & 1 \\
\hline
\end{tabular}

\section{Analysis of the results}

The aim of the study was to find the best piston ring - cylinder liner friction couple based on the minimum amount of wear [11]. Therefore, it was necessary to evaluate the wear and tear of the cylinder liner cooperating with the ring sample. First of all, the trace of cooperation on the surface of the cylinder liner is essential. Zero wear after a week of cooperation at the specified load conditions is practically not feasible. It means poor or no contact at the middle of the ring, where the silver isotope marker is located. No contact causes no wear in this area and excessive wear on the edge of the cylinder liner and the edges of the ring, which will not be detected by the isotopic marker.

This may be caused by deformation, or twist, or other deformation of the ring or cylinder liners in the heat treatment process. Digital photos of traces of cooperation of friction couples are shown in Figs. 23, 24 and 27.
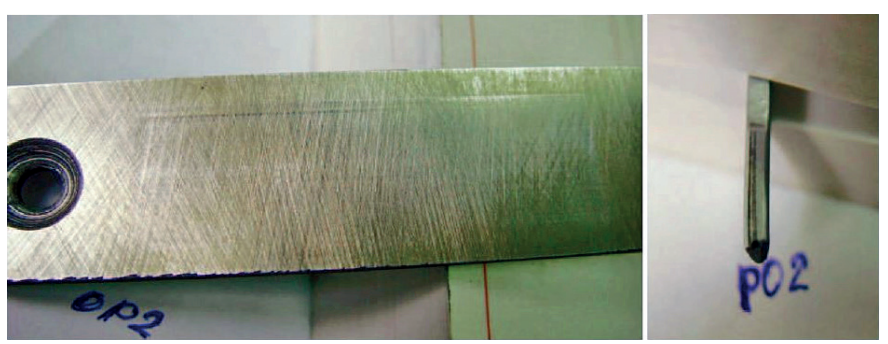

Fig. 24. Traces of cooperation of friction couple OP2-PO2

They show that the best in the assessment of wear is the couple 2 WII-3 (Table 7), which shows no sign of cooperation in the central zone. There is, however, significant wear of the edges, so the sample is rejected. Clear signs of irregular adhesion and flanging make the IP1-IP1 couple classify as seventh in Table 7. Therefore it is not authoritative.

Second in Table 7 is the couple OP2-PO2 with zero wear, which has a steady trace of wear at the cylinder liner and clear traces of cooperation at half height of the ring (Fig. 23). The near absence of the silver isotope marker-based wear in the above case may have been caused by the marker being pressed in too deep or very hard in comparison to the cylinder liner surface of the ring. For full verification, it was necessary to test the hardness and micro-hardness of the ring and cylinder liner and assess the state of the surface by measuring the roughness and micro-waviness. Sample results are shown for the best couple, 1W1-1, in Figs. 25 and 26.

In a collective list of measurements of hardness and surface roughness of the test samples, in Table 8, the couple OP2-PO2 has a micro-hardness of the surface of the ring equal to $1430 \mathrm{HV} 0.05$ and for the cylinder liner in the base, $1210 \mathrm{HV} 0.2$. With the diversity of hardness and change of the roughness from $\mathrm{Ra}=0.9$ and $\mathrm{Rz}=6.5$ in the base portion to $\mathrm{Ra}=0.44$ and $\mathrm{Rz}=2.98$ in the working part of the cylinder liner, in practice, only it was worn. To a large extent, this may 


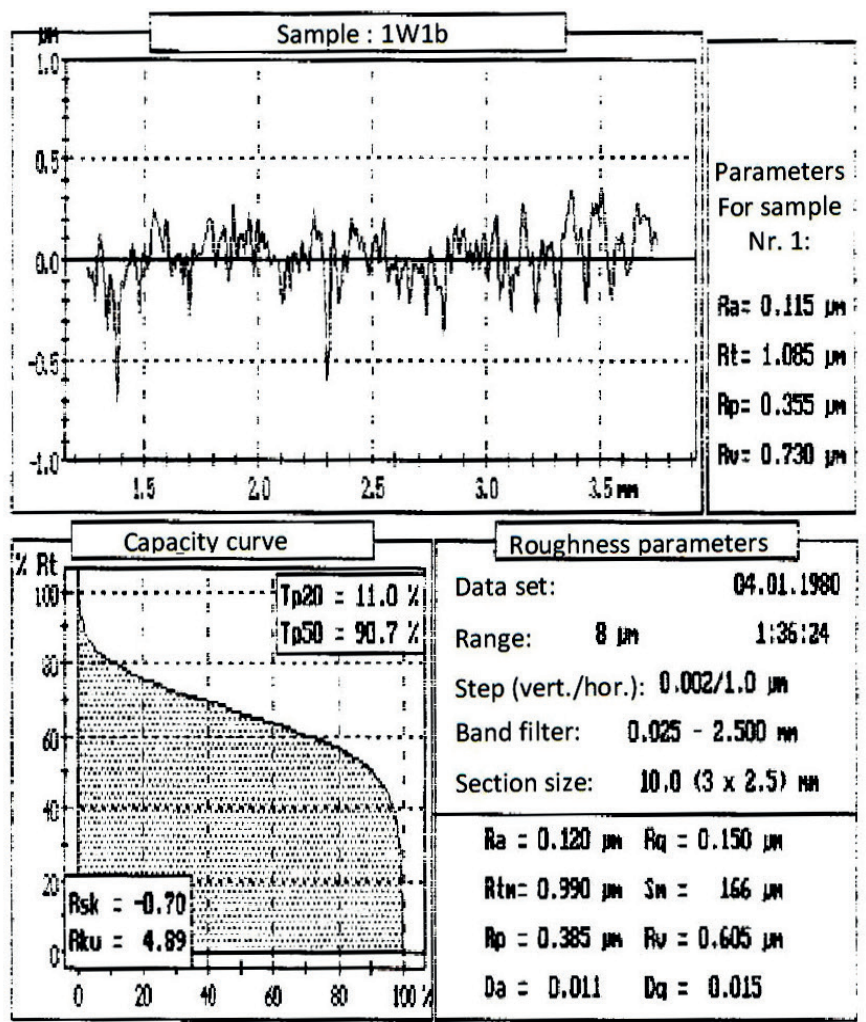

HII PN Profilonetr (BEADIX) Progran B1,EXE R. Puth inski \& J.Tonasik'99

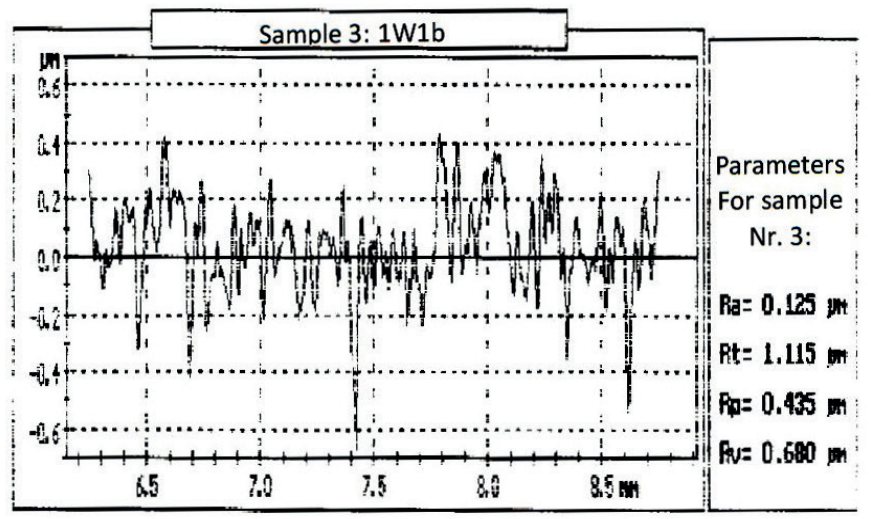

Fig. 25. Sample results of measuring the roughness of base part $1 \mathrm{~W} 1 \mathrm{~b}$ in the cylinder liner

be the effect of edge character on the contact ring (Figs. 25 and 26), hence no indicated wear in the region of the marker in Table 7.

Another couple (No. 3 in Table 7), 1WI-1, according to wear has a very good trace of cooperation on the surface of the cylinder liner with a clear trace of cooperation in the middle of the area (the marker zone), and a discernible trace of wiping on the ring (asymmetric cooperation).

The hardness of the cylinder liner in the base part was 1245 HV0.2, and in the working part it was 1148 HV0.2. Micro-hardness of the surface of the ring was $1080 \mathrm{HV} 0.05$. The surface roughness of the base of the cylinder liner was $R a=0.12$, $\mathrm{Rz}=0.99$, and after the study it was $\mathrm{Ra}=0.09, \mathrm{Rz}=0.75$.

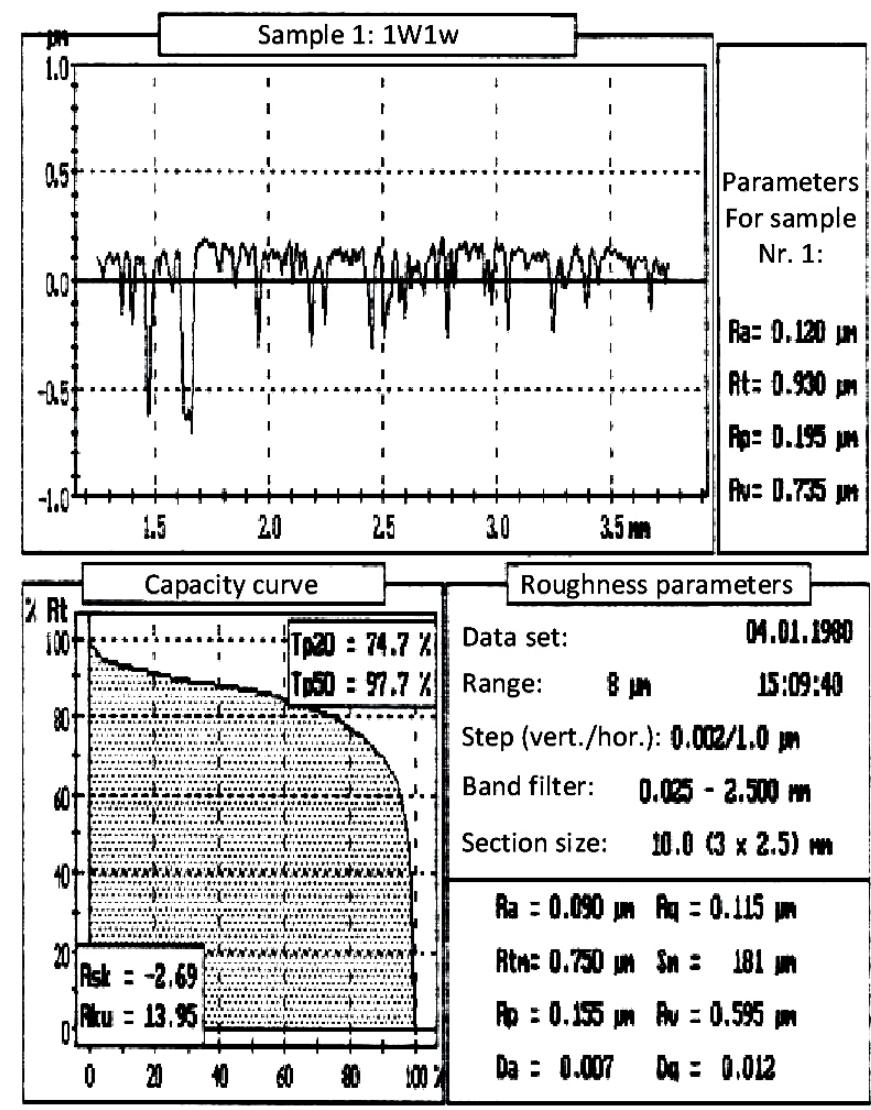

Hith PU Profilonetr (BEDIX) Progran BI.EE R.Autrinski b J.Tonasik'99

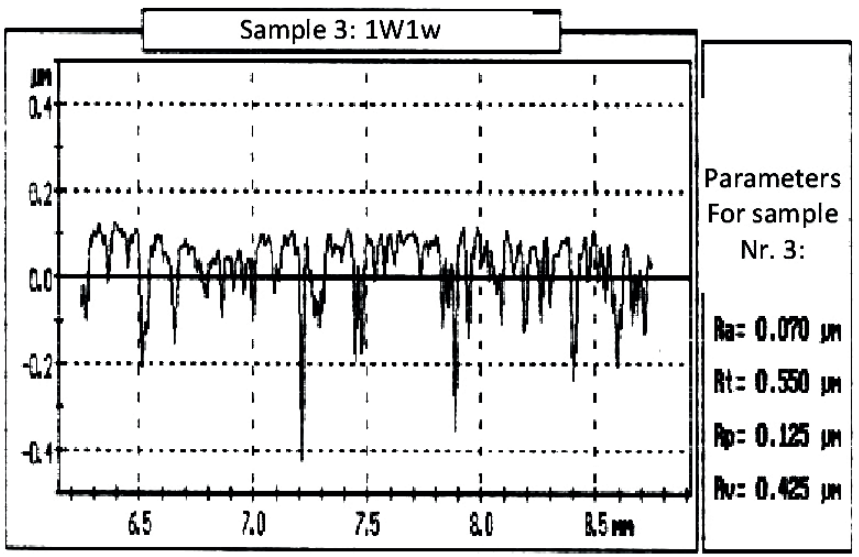

Fig. 26. Sample results of measuring the roughness of the $1 \mathrm{~W} 1 \mathrm{w}$ operating part in the cylinder liner

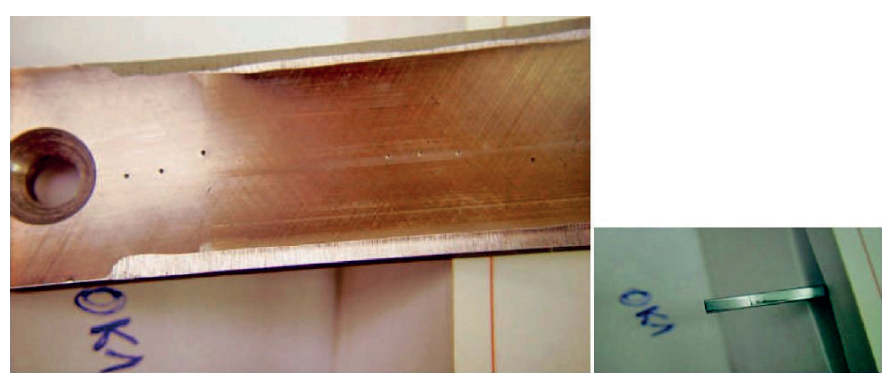

Fig. 27. Traces of cooperation of the OK1-OK1 friction couple 
Table 8

Summary results, measurement of hardness and roughness of the responded friction couples

\begin{tabular}{|c|c|c|c|c|c|c|}
\hline Sample & $\begin{array}{l}\text { Loca- } \\
\text { tion }\end{array}$ & HV0.2 & $\mathrm{Ra}$ & $\mathrm{Rz}$ & $\mathrm{Rp}$ & $\mathrm{Rv}$ \\
\hline $\begin{array}{l}\text { Strip } \\
\text { signature }\end{array}$ & & $\mu \mathrm{m}$ & $\mu \mathrm{m}$ & $\mu \mathrm{m}$ & $\mu \mathrm{m}$ & $\mu \mathrm{m}$ \\
\hline \multirow[t]{3}{*}{$2 \mathrm{WII}$} & W & 1215 & 0.090 & 0.660 & 0.360 & 0.300 \\
\hline & $\mathrm{b}$ & 1166 & 0.170 & 1.130 & 0.450 & 0.680 \\
\hline & P3 & 998HV0.05 & & & & \\
\hline \multirow[t]{3}{*}{$1 \mathrm{~W} 1$} & W & 1148 & 0.090 & 0.750 & 0.155 & 0.595 \\
\hline & $\mathrm{b}$ & 1246 & 0.120 & 0.990 & 0.385 & 0.605 \\
\hline & P1 & 1080HV0.05 & & & & \\
\hline \multirow[t]{3}{*}{$1 \mathrm{WII}$} & W & 1276 & 0.085 & 0.555 & 0.155 & 0.400 \\
\hline & $\mathrm{b}$ & 1245 & 0.285 & 1.755 & 0.570 & 1.185 \\
\hline & P2 & 1193HV0.05 & & & & \\
\hline \multirow[t]{3}{*}{$2 \mathrm{WI}$} & W & 1202 & 0.065 & 0.670 & 0.145 & 0.525 \\
\hline & $\mathrm{b}$ & 1300 & 0.140 & 1.265 & 0.350 & 0.915 \\
\hline & P5 & 1233HV0.05 & & & & \\
\hline \multirow[t]{3}{*}{ IP1 } & W & 1336 & 0.100 & 0.835 & 0.650 & 0.185 \\
\hline & $\mathrm{b}$ & 1255 & 0.205 & 1.850 & 0.550 & 1.300 \\
\hline & pPO1 & $857 \mathrm{HV} 0.05$ & & & & \\
\hline \multirow[t]{3}{*}{ OP1 } & W & 998 & 0.410 & 3.350 & 0.585 & 2.765 \\
\hline & $\mathrm{b}$ & 1179 & 0.605 & 5.080 & 2.00 & 3.080 \\
\hline & pPO1 & 1086HV0.05 & & & & \\
\hline \multirow[t]{3}{*}{ OP2 } & W & 972 & 0.440 & 2.985 & 0.975 & 2.010 \\
\hline & $\mathrm{b}$ & 1210 & 0.900 & 6.535 & 2.510 & 4.025 \\
\hline & pPO2 & 1430HV0.05 & & & & \\
\hline \multirow[t]{3}{*}{$1 \mathrm{~K}$} & W & 988 & 0.645 & 4.795 & 1.310 & 3.485 \\
\hline & $\mathrm{b}$ & 965 & 0.655 & 5.135 & 1.935 & 3.200 \\
\hline & pO2 & 2002HV0.05 & & & & \\
\hline \multirow[t]{3}{*}{ OK1 } & W & 1164 & 0.190 & 2.395 & 0.265 & 2.130 \\
\hline & $\mathrm{b}$ & 960 & 0.125 & 1.150 & 0.445 & 0.705 \\
\hline & pOK1 & 1710HV0.05 & & & & \\
\hline
\end{tabular}

Where:

W - measuring of the operational part of the strip (Fig. 26),

B - measured at the base portion of the strip (Fig. 26),

$\mathrm{P}$ - measuring of the protruding part of the mating ring (the symbol after letter ' $p$ ' is determined by the signature on the ring; Fig. 26).

The fourth couple, OPI-PO1, according to the wear marker of the ring (No. 4 in Table 7) has steady traces of wear on the surface of the cylinder liner and visible traces of symmetrical cooperation on the ring (Fig. 24). The slightly v-shaped track of wear of the ring indicates the setting of the ring according to the direction of travel of the liner once on the first, and once on the second half. The hardness of the cylinder liner in the working part was $998 \mathrm{HV} 0.2$, and of the surface of the ring it was $1086 \mathrm{HV} 0.05$. The surface roughness of the base part of the cylinder liner was $\mathrm{Ra}=0.6$, and after the study it was $\mathrm{Ra}=0.4$.

The fifth couple, 1WII-P2, according to the wear marker of the ring, showed a balanced trace and wiping of cylinder liner similar to the trace of cooperation of the ring of the preceding couple. The hardness of the cylinder liner in the base part was 1245 HV0.2, and the surface of the ring was 1193 HV0.05. The surface roughness of the base part of the cylinder liner was $\mathrm{Ra}=0,28$, and after the study it was $\mathrm{Ra}=0.085$.

Couple No. 8 in Table 7, OK1-OK1, shows signs of edge cooperation with a clear narrow band in the marker zone (Fig. 27). The ring has a larger radius than the cylinder liner and hangs on its edges. After grinding, the study continued. Wear in the central zone of the ring cannot be seen. There are noticeable traces of dulling on the edges, resulting from the cooperation with the edge of the cylinder liner. The hardness of the cylinder liner in the base part was $960 \mathrm{HV} 0.2$, and for the ring it was about $1710 \mathrm{HV} 0.05$. The hardness of the ring was determined with a load of $50 \mathrm{~g}$, and of the cylinder liner with a load of $200 \mathrm{~g}$. This was due to the large micro-hardness $(15-20 \mu \mathrm{m})$ of the surface of the ring and decrease thereof in the area of galvanic chromium.

Micro-hardness measurements were carried out on a hardness tester, model Zwick 3212. The results in Table 8 contain the average values from six measurements. The measurements of roughness were carried out on a profilometer made by Bendix [2, 11].

\section{Conclusions}

To achieve the best results, the tests were conducted according to the following criteria:

- minimum wear of the two contact surfaces

- the state of the surface (roughness)

- uniformity of the signs of cooperation

- in the case of increased wear - friction couples with numbers 3, 4, 5 (as in Table 7).

Couple No. 2 had the best results, but it was not fully reliable. In the case of couples 3, 4, and 5, the hardness of the cylinder liner was higher than the hardness of the surface of the ring by an average of 166,93 , and $52 \mathrm{HV}$, respectively. In the case of couple No. 2, the ring was harder by an average of $220 \mathrm{HV}$ compared to the cylinder liner.

The worst pairs, according to the wear criterion of the ring, were the friction couples No. 6 and 8, which had the rings harder than the cylinder liner by 1030 and $750 \mathrm{HV}$ respectively.

It seems that a good combination, due to the minimum amount of abrasive wear, should not have much difference in hardness, but it should not be too close either. The maximum difference in the results above should not exceed $200 \mathrm{HV}$, and the minimum should not be less than $50 \mathrm{HV}$ (for the established criterion for differentiation, HV0.2 and HV0.05). The 
size and depth of the etched mesh of lubrication pockets on the surface of the ring is also important. Better results were given by the friction couple with a thicker and deeper mesh (a mesh of lubrication pockets that are larger than average but not extreme). The pocket depth should be around 0.01-0.02 $\mathrm{mm}$. In the process of chromium electroplating, the cracks should be minimized reaching down to half the thickness of the chromium layer $(0.15 \mathrm{~mm})$, particularly those extending to the substrate. This can lead to cracking, chipping and kickback of the chromium layer. It is recommended to use a traditional honing fit of the cylinder liner with the surface structure with the "cross" shape. However, due to increased wear in the area of the top dead position of the piston, the creation of a "lubricant trays" zone by laser micromachining is suggested. It should be noted that the method of testing the wear of friction couples of the sample cylinder liner and piston ring, despite the modification of the bench, does not guarantee full adequacy of actual engine operating conditions. In some friction couples, there was edge wear of isotope inserts (which were placed in the center of the ring sample), which did not reflect the actual wear process. The average speed in the studies was several times lower than in real conditions (shorter stroke of $60 \mathrm{~mm}$ in the studies and $175 \mathrm{~mm}$ in real engines), while the average pressure was several times larger. Lubrication on the bench was 1 drop per minute, and in the engine, it is $2 \times n$ per minute. The temperature of the head of the ring was $t=110^{\circ} \mathrm{C}$. Under these conditions, there is no oil film. There is practically no possibility of raising the lubricant wedge. Mixed friction could exist only temporarily (after the oil drop lands). Evaluation of ring wear was achieved by the use of nuclear markers made out of silver isotopes. Wear of the cylinder liner samples was evaluated visually and by measuring the micro-roughness of worked and base surface. Due to different conditions of base areas for each sample of cylinder liners (polished, honed, turned), a fully meaningful comparison is difficult. Attention should be drawn to the size of the etching on the surface of the lubrication pocket mesh on the ring (its spacing and depth of the pockets). These are artificially-made lubrication pockets that have a beneficial impact on the stability of friction couples. In the cross-section rings, visible wedge-shaped gaps, reaching from the surface of the chromium layer to the substrate, are not preferred. To sum up, a complete and more reliable assessment of the proposed technology can be obtained after performing durability bench tests of the engine.

\section{REFERENCES}

[1] W. Ostapski, "Analysis of thermo-mechanical response in an aircraft piston engine by analytical, FEM, and test-stand investigations", Journal of Thermal Stresses 34, 285-312 (2011).

[2] W. Ostapski, "Raport projektu celowego nr 6 T08 154 2001C/5673: Wdrożenie technologii wytwarzania kompozytowych, dyfuzyjnych warstw przeciwzużyciowych w produkcji elementów silników lotniczych" 2002-2005, 2006, [in Polish].

[3] T. Burakowski and T. Wierzchoń, Surface Engineering of Metals: Principles, Equipment, Technologies, CRC Press, New York, 1999.

[4] T. Wierzchoń, J. Rudnicki, M. Hering, and R. Niedbała, "Formation and properties of nitrided layers produced in pulsed plasma at a frequency between 10 and $60 \mathrm{kHz}$ ", Vacuum 48 (6) 499-502 (1997).

[5] T. Wierzchoń, "Structure and properties of multicomponent and composite layers produced by combined surface engineering methods", Surface and Coatings Technology 180-181, 458-464 (2004).

[6] M. Tacikowski, I. Ulbin-Pokorska, and T. Wierzchon, "Microstructure of the composite oxynitrided chromium layers produced on steel by a duplex method", Surface and Coatings Technology 201, 2776-2781(2006)

[7] PN-83 H-04302, "Badania wytrzymałościowe metali. Próba tarcia w układzie: 3 wałeczki-stożek", [in Polish].

[8] A. Jarkiewicz, E. Roliński, and T. Wierzchoń, "Experimental determination of influence of residual stresses on thermochemical processes in tool steels", Materials Science and Technology 2, 635-629 (1986)

[10] W. Ostapski, "Introductory analysis of causes of decreasing operating of Asz-62IR aircraft engine", IX Polish-Ukrainian Conf. on "CAD in Machinery Design", Poland, 109-120 (2001).

[11] W. Ostapski, "Test stand examinations and analysis of wear in aircraft piston engines", Proc. VI Conf. The Control of Fluid Systems, Slovakia, (2001).

[12] W. Ostapski, "Optimization of surface layer parameters of frictional pair ring-cylinder bearing surface of ASz-62IR aircraft engine with regard to abrasive wear criterion", IX Polish-Ukrainian Conf. on "CAD in Machinery Design", Poland, 121-130 (2001). 